\title{
Optimization and Characterization of Palm Oil-based Nanoemulsion Loaded with Parthenium hysterophorus Crude Extract for Natural Herbicide Formulation
}

\author{
Noorul Jannah Zainuddin ${ }^{1,3 *}$, Siti Efliza Ashari, ${ }^{1,3,4 *}$, Norazlinaliza Salim ${ }^{1,3,4}$, \\ Norhayu Asib², Dzolkhifli Omar², and Gwendoline Ee Cheng Lian ${ }^{3}$ \\ ${ }^{1}$ Integrated Chemical Biophysics Research, Faculty of Science, Universiti Putra Malaysia, 43400 UPM Serdang, Selangor, MALAYSIA \\ ${ }^{2}$ Department of Plant Protection, Faculty of Agriculture. Universiti Putra Malaysia, 43400 UPM Serdang, Selangor, MALAYSIA \\ ${ }^{3}$ Department of Chemistry, Faculty of Science, Universiti Putra Malaysia, 43400 UPM Serdang, Selangor, MALAYSIA \\ ${ }^{4}$ Centre of Foundation Studies for Agricultural Science, Universiti Putra Malaysia, 43400 UPM Serdang, MALAYSIA
}

\begin{abstract}
The present study revealed the optimization of nanoemulsion containing palm oil derivatives and Parthenium hysterophorus $\mathrm{L}$. crude extract (PHCE) as pre-emergence herbicide formulation against Diodia ocimifolia. The nanoemulsion formulation was prepared by high energy emulsification method, and it was optimized by mixture experimental design (MED). From the optimization process, analysis of variance (ANOVA) showed a fit quadratic polynomial model with an optimal formulation composition containing $30.91 \%$ of palm kernel oil ester (PKOE), 28.48\% of mixed surfactants (Tensiofix and Tween 80, 8:2), $\mathbf{2 8 . 3 2 \%}$ of water and $\mathbf{1 2 . 2 9 \%}$ of PHCE. The reading of both experimental and predicted particle size in the verification experiment were acceptable with a residual standard error (RSE) was less than $2 \%$. Under the optimal condition, the smallest particle size obtained was $140.10 \mathrm{~nm}$, and the particle was shown by morphology analysis to be spherical and demonstrated good stability (no phase separation) under centrifugation and different storage conditions $\left(25 \pm 5^{\circ} \mathrm{C}\right.$ and $\left.45^{\circ} \mathrm{C}\right)$. Nanoemulsion stored for 60 days exhibits monodisperse emulsion with a slight increase of particle size. The increase in particle size over time might have contributed by Ostwald ripening phenomenon which is shown by a linear graph from Ostwald ripening rate analysis. In the in vitro germination test, $P$. hysterophorus nanoemulsion (PHNE) was shown to cause total inhibition of $D$. ocimifolia seed at lower concentration $\left(5 \mathrm{~g} \mathrm{~L}^{-1}\right)$ as compared to PHCE $\left(10 \mathrm{~g} \mathrm{~L}^{-1}\right)$. The finding of the research could potentially serve as a platform for the development of palm oil based formulation containing plant crude extract for green weed management.
\end{abstract}

Key words: palm oil esters, nanoemulsion, $P$. hysterophorus, herbicide, natural, weed management, optimization

\section{Introduction}

Parthenium hysterophorus is one of the world's seven most devastating and aggressive weed commonly known as carrot grass and bitter weed ${ }^{1)}$. The Asteraceae family belonging weeds were often spotted on abandoned lands, drainage and railway tracks. Parthenium hysterophorus contained allelochemical parthenin which play as a major phytotoxic compound in the plant. Allelochemical is a chemical compound that influences growth, survival, and reproduction of other organism ${ }^{2}$. Due to its noxious ability, $P$. hysterophorus could be exploited as a potential bioactive component in herbicide formulation for natural weed management $t^{3)}$.
In this study, P. hysterophorus crude extract (PHCE) was formulated in nanoemulsion as a delivery system to deliver the bioactive compounds through hydrophobic plant surface. The system has been successfully used in various field of studies such as cosmetic, pharmaceuticals, food, heavy metal, and agriculture due to its uniform and extremely small particle size. It is a novel scientific approach that involves the use of materials and equipment capable of manipulating physical as well as chemical properties of a substance at molecular levels. The diffusion of active ingredients into plant tissue could be improved by adjusting the molecular size and lipophilicity since penetration into the plant is a prerequisite for the efficacy of her-

\footnotetext{
*Correspondence to: Noorul Jannah Zainuddin and Siti Efliza Ashari. Integrated Chemical Biophysics Research, Faculty of Science, Universiti Putra Malaysia, 43400 UPM Serdang, Selangor, MALAYSIA

E-mail: jannahzainuddin @gmail.com (Zainuddin, N.J), ctefliza@upm.edu.my (Ashari, S.E.)

Accepted May 20, 2019 (received for review October 22, 2018)

Journal of Oleo Science ISSN 1345-8957 print / ISSN 1347-3352 online

http://www.jstage.jst.go.jp/browse/jos/ http://mc.manusriptcentral.com/jjocs
} 
bicides formulation. Previous studies have shown that nanoemulsion of herbicide formulation containing glyphosate has been successfully developed which the result in turn has improved efficiency of commercial glyphosate herbicide $\left(\right.$ Roundup ${ }^{\circledR}$ ) against Eleusine indica ${ }^{4}$.

One of the highest motivation on development of new agriculture product was to produce a formulation that is less harmful to the ecosystem ${ }^{5}$. Vegetable oils such as palm kernel oil ester (PKOE) could act as natural alternatives solvent to replace the toxic and non-renewable conventional adjuvants such as xylene and petroleum oil ${ }^{6)}$. The presence of fatty acid ester from PKOE in herbicide formulation, has the similar ability as petroleum oils (eg: petroleum distillates, gasoline, and kerosene) to disrupt membranes of a plant cell in surface cells, leading to the death of plant tissues ${ }^{7}$. In addition, according to Sharma and Singh $(2000)^{8)}$, oil in the form of esters could improve herbicide effectiveness compared to non-esterified rapeseed oil or mineral oil adjuvants. In comparison to petroleum oils which is slow to degrade by the environment, PKOE was produced by high quality resourceful natural products, preparation under mild condition reaction, and utilizing environmental friendly lipase as biocatalyst ${ }^{9)}$. The wax ester was also considered to have good characteristics such as safe for handling due to nontoxic, less greasy and nonirritant properties, a good wetting agent, thermal stability and better storage ${ }^{10)}$. To the extent of our knowledge, we believe that the used of PKOE as one of the adjuvants in herbicide formulation has not been investigated before.

Characteristic of nanoemulsion system was greatly depending on the variation of its composition (water, surfactant and active ingredient). Statistical tools such as mixture experimental design (MED) and analysis of variance (ANOVA) offer a strategic way to achieve the optimized formulation with desirable attributes. Optimization process refers to a method to maximize the benefits from a system, process or a product using multivariate statistic techniques ${ }^{11)}$. These methods have been largely accepted in applied chemistry to replace the traditional one factor at a time experimental design. This is driven by its ability to minimize the number of an experimental run for cost and time effective works. In addition, the maximum amount of information about the variables affecting the system could be yield out from this statistical approaches ${ }^{12}$. Several researches have been successfully reported the used of MED and ANOVA in development of nanoemulsion for drug delivery and cosmetic application ${ }^{13,14)}$. Both studies reported the effect of nanoemulsion compositions (independent variables) on achieving the minimum mean particle size as the desired response. However to date, the used of MED in agriculture formulation remain less explored and there was no scientific study reported on the optimization of nanoemulsion containing palm oil derivatives (PKOE) and plant crude extract by using MED for herbicide formulation.
Therefore, the ultimate goal of this study is to design and develop a palm-based nanoemulsion containing $P$. hysterophorus crude extracts for an efficient herbicide formulation against weed in Malaysian palm oil plantation, slender button weed (Diodia ocimifolia).

\section{Materials and Methods}

\subsection{Materials}

Parthenium hysterophorus plant was collected from Kampung Sentosa, Semenyih, Selangor $\left(2^{\circ} 56^{\prime} 46.6 \mathrm{~N} 101^{\circ}\right.$ $50^{\prime} 56.6 \mathrm{E}$ ) with the permission and guide from the Department of Agriculture Selangor, Malaysia. Palm kernel oil esters (PKOE) was prepared in our lab according to the method used by Keng et al. ${ }^{9)}$ Tween 80 were obtained from Sigma Aldrich (Germany). Tensiofix EW70 was given by Ajinomoto OmniChem(Belgium) as a gift. Deionized water was prepared from a Milli-Q water system (Milipore, USA). Methanol used in this study was analytical grade and purchased from J.T Baker(USA).

\subsection{Extraction of $P$. hysterophorus}

Mature plants of $P$. hysterophorus were collected, sun dried and ground into fine powder by a grinder. Sufficient quantity of $P$. hysterophorus powder $(100 \mathrm{~g})$ was macerated with $600 \mathrm{~mL}$ of methanol $\left(\mathrm{CH}_{3} \mathrm{OH}\right)$ for $24 \mathrm{~h}$. After filtration, the obtained solution was concentrated by using rotary evaporator (Rotavapor R-210, Buchi, Switzerland) resulting in a green paste of crude extract. The crude extract was stored at $-20^{\circ} \mathrm{C}$ prior to further processes to avoid deterioration.

\subsection{Preparation of $P$. hysterophorus nanoemulsion (PHNE)}

PHNE was prepared by high-shear stirring emulsification method at room temperature $\left(25.0 \pm 0.5^{\circ} \mathrm{C}\right)$. Refer to the composition in Table 2, PHCE was first mixed with PKOE to form the oil phase. Next, Tensiofix EW70 and Tween 80 were blended at ratio $8: 2(\mathrm{w} / \mathrm{w})$ before the mixture of surfactants water were added into the oil phase and consequently homogenized at $1300 \mathrm{rpm}$ for 25 min using high shear homogenizer (Ika T25 digital Ultra Turrax ${ }^{\circledR}$, USA). The composition of each component in nanoemulsion was determined by statistical analysis in mixture experimental design (MED).

\subsection{Mixture experimental design (MED)}

The effect of multiple parameters of PHNE: Tensiofix: Tween 80 (8:2) (A): PKOE (B); water (C); PHCE (D), on a response (particle size) using MED were studied. The constrains of the component proportions were listed in Table 1. In the MED design, the restriction was created as a barrier to prevent the experimenter from exploring the 
Table 1 Constraints of independent variable proportions.

\begin{tabular}{ccc}
\hline Independent variables, $X_{j}$ & Lower limit, $L_{j}$ & Upper limit, $U_{j}$ \\
\hline Tensiofix: Tween $80(8: 2)(\mathrm{A})$ & 25.00 & 35.00 \\
PKOE (B) & 30.00 & 40.00 \\
Water (C) & 7.00 & 39.00 \\
PHCE (D) & 6.00 & 18.00 \\
\hline
\end{tabular}

entire samples region. The general form of restrictions of the component, $\mathrm{Xj}$ was shown in Equation(1).

$$
\sum X j=I \text { and } L j \leq X j \geq U j
$$

Where $X j$ is the independent variables, $L j$ is the lower limit of variables and $U j$ is the upper limit of variables. Design matrix with a total of 20 runs was generated and statistically analyzed using Design Expert version 7.0.0 by Stat. Ease Inc., (Minneapolis, USA). Each experiment was run randomized following the D-optimal model design to minimize the effect of extraneous factors on actual response.

2.4.1 Statistical analysis for optimization process

Analysis of variance (ANOVA) was carried out to determine the significant differences among independent variables. A good reduced model was presented as $p$-value less than $0.05(p<0.05)$, which considered as significant and having a high correlation coefficient $\left(\mathrm{R}^{2}>0.9\right)$.

\subsubsection{Verification of the model}

The adequacy of the obtained model was tested by preparing several random formulations to validate the model prediction. The differences between predicted values and experimental value were obtained by calculating the residual standard error (RSE) as shown in Equation(2).

$$
\begin{aligned}
\operatorname{RSE}(\%)= & (\text { Experimental value-predicted value }) /(\text { Pre- } \\
& \text { dicted value }) \times 100
\end{aligned}
$$

\subsection{Characterization of optimized PHNE}

2.5.1 Mean Particle Size and Polydispersity Index (PDI)

The particle size and PDI value were determined by dynamic light scattering (DLS) particle size analyzer with an angle of $173^{\circ}$ at room temperature $\left(25.0 \pm 0.5^{\circ} \mathrm{C}\right)$. The measurement was performed using Malvern, Zetasizer Nano ZS90 (UK). Each sample was diluted with deionized water (1:200) prior to analysis. Measurements were repeated three times and the average particle size was expressed as the mean diameter.

\subsubsection{Stability study}

Long term physical stability of optimized nanoemulsion was predicted by stability test at room temperature $(25 \pm$ $2^{\circ} \mathrm{C}$ ) for 90 days, storage at $45^{\circ} \mathrm{C}$ for 14 days, and stability under centrifugation (sample was subjected to centrifugal force for $15 \mathrm{~min}$ at $4000 \mathrm{rpm}$ ). The optimal nanoemulsion was also tested on long term stability by measuring particle size at different time intervals for 60 days and calculating the Ostwald ripening rate $\left(r^{3}\right.$ versus t). According to the Lifshitz-Slesov-Wagner theory, a linear relationship between $r^{3}$ and time indicated that Ostwald ripening phenomenon obtained in the production of curcumin-loaded MCT nanoemulsion ${ }^{15)}$. The Ostwald ripening rate was quantitatively calculated using Equation(3):

$$
r^{3}=\frac{8}{9}\left[\frac{C(\infty) \gamma V_{m} D}{\rho R T}\right] t
$$

where $r$ is the average radius after time, $\mathrm{C}(\infty)$ is the bulk phase of solubility, $\gamma$ is the interfacial tension between the dispersed phase and continuous phase, $V_{m}$ is the molar volume of the internal space, $D$ is the diffusion coefficient of the dispersed phase in the continuous phase, $\rho$ is the density of the dispersed phase, $\mathrm{R}$ is the gas constant, $\mathrm{T}$ is the absolute temperature and $t$ is the storage time in seconds.

2.5.3 Field eission mcroscope (FEM) masurement

The morphology of optimized nanoemulsion was characterized by using a field emission microscope (FEM) (JOEL JEM-2100F, Japan). For preparation, negative staining method was used where the sample was diluted in deionized water and homogenized. A Formvar copper grid was placed on one drop of diluted nanoemulsion, and allowed to equilibrate at room temperature $\left(25 \pm 2^{\circ} \mathrm{C}\right)$ for $5 \mathrm{~min}$. The grid was then stained with $2 \%$ phosphotungstic acid solution. Excess liquid and prepared sample were air-dried prior to analysis.

2.5.4 Surface tension masurement

The surface tension of PHNE and PHCE at different concentration was measured at $25^{\circ} \mathrm{C}$ with Kruss tensiometer(Kruss, UK), using a platinum plate as referred to the Du Noüy ring method ${ }^{16)}$. In every set of measurement, the plate was first rinsed with distilled water and heated to red-orange colour to clean it. The tensiometer was calibrated using distilled water with a surface tension of 72-73 $\mathrm{mN} \mathrm{m}{ }^{-1}$ for every sample measured. Measurement was carried out five times at intervals of $10 \mathrm{~min}$. The PHCE and PHNE solutions were prepared by dissolving the amount of extract or nanoemulsion in $500 \mathrm{~mL}$ of water by stirring using a glass rod. Dilutions were made to establish four concentrations: $1,2,5,10$ and $15 \mathrm{~g} \mathrm{~L}^{-1}$ of crude extract in water. 


\section{N. J. Zainuddin, S. E. Ashari, N. Salim et al.}

\subsection{In vitro study of PHNE against Diodia ocimifolia seed germination}

2.6.1 Preparation of PHNE Solution

The PHNE solutions were prepared by dissolving an amount of nanoemulsion in $500 \mathrm{~mL}$ of water by stirring using a glass rod. Dilutions were made to establish four concentrations: $1,2,5,10$ and $15 \mathrm{~g} \mathrm{~L}^{-1}$ of crude extract in water.

2.6.2 Pretreatment of $D$. ocimifolia seeds

The seeds were tested for its viability by immersing in water for $24 \mathrm{~h}$, and the sank seeds were preserved as viable seeds. To break the seed dormancy, viable seeds were soaked once again for $24 \mathrm{~h}$ in gibberellic acid solution (0.25 $\mathrm{g}$ in $250 \mathrm{~mL}$ distilled water). Seeds were ready for use after being rinsed with distilled water three times.

2.6.3 Seed growth bioassay

Seed germination bioassay was carried out in the laboratory to assess the seed germination and seed growth of $D$. ocimifolia seeds as affected by PHCE and PHNE. Six petri dishes (each $9 \mathrm{~cm}$ in diameter) containing one layer of Whatman filter paper No. 1 were impregnated with $10 \mathrm{~mL}$ of PHCE or PHNE solutions at concentration 1,2,5,10 and $15 \mathrm{~g} \mathrm{~L}^{-1}$. Then, $10 \mathrm{~mL}$ of distilled water was added to each petri dishes (as additional water to allow seed germinate) before $20 \mathrm{D}$. ocimifolia seeds were evenly arranged on the treated filter papers. A control petri dish treated with 20 $\mathrm{mL}$ distilled water was set as a negative control. The in vitro seed germination test was replicated three times. The petri dishes were covered with lids and allowed for the seed to germination at $12 \mathrm{~h}$ of light to $12 \mathrm{~h}$ of dark condition continuously for 14 days at constant temperature (25 $\pm 5^{\circ} \mathrm{C}$ ). To keep the filter paper moistened, distilled water was added on a daily basis. After 14 days, seed germination was visually counted in each of the replicated treatment and converted into seed germination (\%). The growth of $D$. ocimifolia seed was compared between treatment by PHCE and PHNE where treatment by PHNE work as the positive control. Germination percentage (GP) was calculated by the following Equation(4).

$$
\begin{aligned}
\mathrm{GP}(\%)= & (\text { Number of germinated seeds } / \text { (Total number } \\
& \text { of seeds }) \times 10
\end{aligned}
$$

\subsubsection{Statistical analysis for seed germination}

Data collected from seed germination and seed growth (length of radicle and shoots) were replicate four times. All measurements were tested and compared by analysis of variance (ANOVA) and evaluation of Tukey's test with a confidence interval of $95 \%$, using Minitab ${ }^{\circledR}$, version 16 (Minitab Inc., USA). Data were presented with standard errors (SE).

2.6.5 Dose response regression

The dose response curves of seed germination were constructed by GraphPad Prism 7 Software by fitting the
Equation(5):

$$
\mathrm{Y}=100 /\left(1+10\left(\left(\log \mathrm{ED}_{50}-\mathrm{X}\right) \mathrm{A}\right)\right)
$$

where $\mathrm{Y}$ axis represents the percentage of relative germination $(\mathrm{RG} \%)$, $\mathrm{X}$ axis represents log concentration of the prepared solution, $\mathrm{ED}_{50}$ is the half maximal effective dose and $\mathrm{A}$ is the hill slope value. The goodness of dose response model was evaluated by the coefficient of determination $\left(\mathrm{R}^{2}\right)$. Ina germination experiment, the relative germination $(\mathrm{RG})$ was calculated by referring to the Equation (6):

$$
\mathrm{RG}(\%)=\mathrm{E} / \mathrm{C} \times 100
$$

where $\mathrm{E}$ is the mean value of the germinated seed in treated sample and $\mathrm{C}$ is the mean value of germinated seed for control set.

\section{Results and Discussion}

\subsection{Fitting the MED model and analysis of variance (ANOVA)}

From the mixture experimental design (MED), a total of 20 experiments were carried out. A quadratic model was suggested to be the best model that would fit the analysis. Table 2 displayed the experimental and predicted values for the particle size of PHNE under the different composition of surfactants (Tensiofix and Tween 80), oil (PKOE), water and PHCE. The prediction of particle size was based on the experimental data given in term of coded factors as shown by Equation(7).

$$
\begin{aligned}
\mathrm{Y}= & 8212.03 \mathrm{~A}+2151.23 \mathrm{~B}+8083.54 \mathrm{C}+4226.76 \mathrm{D}- \\
& 12635.49 \mathrm{AB}-29851.05 \mathrm{AC}-11276.51 \mathrm{AD}- \\
& 11496.08 \mathrm{BC}-7921.51 \mathrm{BD}-13018.79 \mathrm{CD}
\end{aligned}
$$

where A, B, C, and D represent independent variables of surfactant content, oil content, water content, and PHCE content in w/w (\%) respectively. From the equation, the graph of the predicted and actual values of particle size was plotted (Fig. 1) and displayed a good fit where the points are close to the regressed diagonal line, with narrow confidence bands.

Table 3 presented the analysis of variance (ANOVA) for the MED of the quadratic model to examine the suitability and significance of the final model. ANOVA works by checking the individual variability over the response. The analysis was used to determine statistical significance between the means of independent variables. A good $\mathrm{R}^{2}$ value (0.9933) indicated the accuracy of predicted and experimental data. The predicted $R^{2}$ value displayed to be in reasonable agreement with adjusted $\mathrm{R}^{2}$ value, showing that the model has predicted the response well. The model was statistically significant at 95\% confidence level by having a high F-value (130.91). ANOVA analysis identifies the model 
Table 2 Experimental and predicted values of particle size for PHNE from MED.

\begin{tabular}{ccrrrrr}
\hline \multirow{2}{*}{ Experiment No. } & A & \multirow{2}{*}{$\mathrm{B}$} & $\mathrm{C}$ & $\mathrm{D}$ & \multicolumn{2}{c}{ Particle size (nm) } \\
\cline { 6 - 7 } & & & & & Experimental & Predicted \\
\hline 2 & 35.00 & 30.00 & 23.00 & 12.00 & 247.77 & 244.94 \\
3 & 30.00 & 35.00 & 23.00 & 12.00 & 170.10 & 173.11 \\
4 & 35.00 & 40.00 & 19.00 & 6.00 & 311.07 & 321.08 \\
5 & 30.00 & 35.00 & 23.00 & 12.00 & 161.83 & 173.11 \\
6 & 30.00 & 40.00 & 24.00 & 6.00 & 169.67 & 168.04 \\
7 & 35.00 & 35.00 & 24.00 & 6.00 & 217.30 & 209.16 \\
8 & 25.00 & 35.00 & 34.00 & 6.00 & 189.60 & 195.89 \\
9 & 25.00 & 30.00 & 33.00 & 12.00 & 185.20 & 185.66 \\
10 & 25.00 & 40.00 & 17.00 & 18.00 & 253.53 & 258.40 \\
11 & 30.00 & 35.00 & 23.00 & 12.00 & 178.13 & 173.11 \\
12 & 35.00 & 40.00 & 7.00 & 18.00 & 450.00 & 422.00 \\
13 & 25.00 & 40.00 & 29.00 & 6.00 & 172.43 & 164.25 \\
14 & 25.00 & 40.00 & 29.00 & 6.00 & 163.93 & 164.46 \\
15 & 30.00 & 35.00 & 23.00 & 12.00 & 169.33 & 173.11 \\
16 & 30.00 & 30.00 & 34.00 & 6.00 & 148.20 & 145.24 \\
17 & 30.00 & 30.00 & 34.00 & 6.00 & 142.50 & 145.24 \\
18 & 32.50 & 37.50 & 15.00 & 15.00 & 407.00 & 392.09 \\
19 & 25.00 & 30.00 & 27.00 & 18.00 & 185.87 & 180.04 \\
20 & 35.00 & 30.00 & 17.00 & 18.00 & 422.33 & 428.88 \\
\hline & 25.00 & 30.00 & 39.00 & 6.00 & 221.30 & 285.01 \\
\hline
\end{tabular}

Note: $\mathrm{A}=$ Tensiofix: Tween $80, \mathrm{~B}=\mathrm{PKOE}, \mathrm{C}=$ water and $\mathrm{D}=\mathrm{PHCE}$

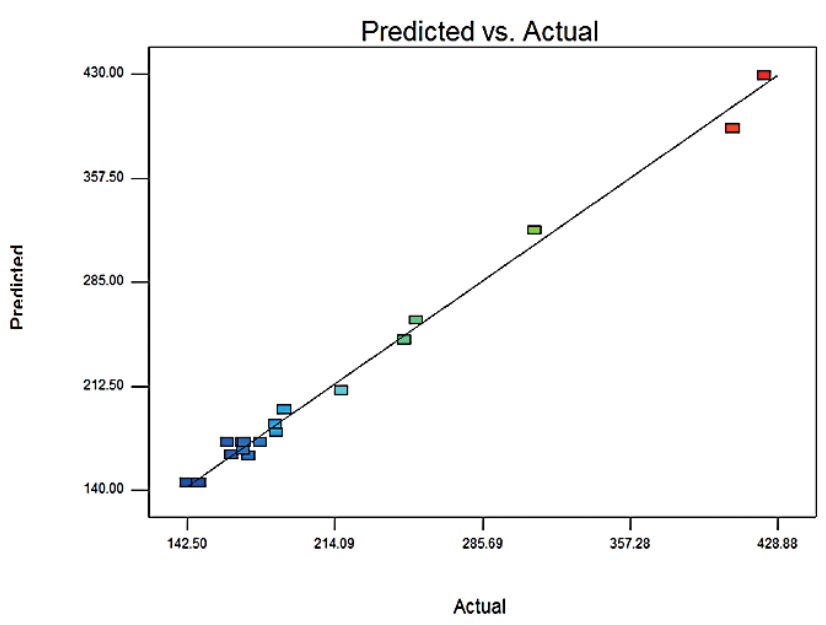

Fig. 1 Predicted and experimental value of particle size of PHNE.

having not significant lack of fit and value of $p<0.0001$ which implies model was significant.

\subsection{D-Optimal analysis}

Selection of optimum composition was driven by a com- bination of multivariate variables which gave the lowest particle size. Three-dimensional(3D) surface graph was plotted using Design Expert software to analyze and visualize the interaction between variables. Figure 2 showed the effect of Tensiofix: Tween 80(A), PKOE (B) and PHCE (D) as water $(\mathrm{C})$ was kept constant. The particle size of nanoemulsion was first decreased with increasing the amount of Tensiofix: Tween 80(A), PKOE(B) and PHCE(D). However, particle size increased as the amount of this three component continues to be added on. This generally contributed by the fact that surfactant work by covering the oil droplet and led to reducing the interfacial tension between water and oil. As a protective coating, surfactant inhibits particle aggregation by reducing the Laplace pressure and prevent coalescence ${ }^{17)}$ to produce small particle size. A similar observation was reported by Musa et al. ${ }^{11}$ where particle size decreased as the amount of surfactant increased. However, at one point, the particle size increased as a result of self-assembly of surfactant after achieving the critical micelle concentration (CMC). Under this situation,a specific amount of surfactants were introduced into oil in water interface to form an emulsion, and the excess free surfactant may form aggregates by self-as- 


\section{N. J. Zainuddin, S. E. Ashari, N. Salim et al.}

Table 3 Analysis of variance (ANOVA) for the MED of the quadratic model.

\begin{tabular}{lcccccc}
\hline \multicolumn{1}{c}{ Source } & Sum of squares & Df & Mean square & F value & p-value & Significance \\
\hline Model & 117700.00 & 9 & 13074.48 & 130.91 & $<0.0001$ & Significant \\
Linear mixture & 69373.82 & 3 & 23124.61 & 231.54 & $<0.0001$ & \\
Residual & 798.97 & 8 & 99.87 & & & \\
Lack of fit & 649.52 & 4 & 162.38 & 4.35 & 0.0919 & Not significant \\
Pure error & 149.46 & 4 & 37.36 & & & \\
Cor total & 118500.00 & 17 & & & & \\
$\mathrm{R}^{2}$ & 0.9933 & & & & & \\
$\mathrm{R}^{2}$ (predicted) & 0.9284 & & & & & \\
$\mathrm{R}^{2}$ (adjusted) & 0.9857 & & & & & \\
Regression & $<0.0001$ & & & & & \\
(p-value) & & & & & & \\
\hline
\end{tabular}

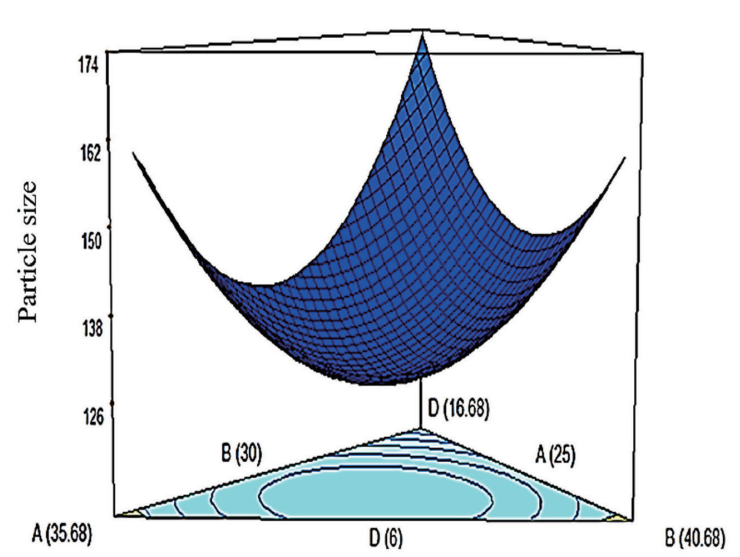

(a)

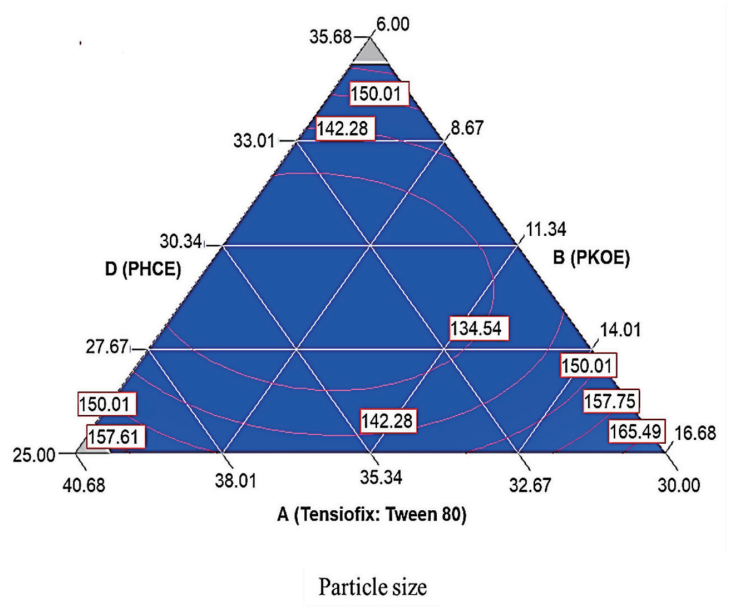

(b)

Fig. 2 The (a)3D diagram and (b) contour plot illustrated the effect of the composition of Tensiofix: Tween 80 (A), PKOE (B) and PHCE (D) on the particle size of PHNE as the amount of water (C) was kept constant. sembled with the emulsion particles ${ }^{18)}$.

On the other hand, high concentration of PKOE could increase the viscosity of the formulated system as a result of increasing of flow resistance and restriction on the break-up rate ${ }^{19)}$. Additionally, too much of oil resulted in incomplete coverage of surfactant molecule on to the oil droplets, and insufficient to reduce the interfacial tension at oil in water interface. Addition of a large amount of PHCE could result in the same way as oil. This fact could be explained by deposition of mixture substances (plant crude extract), which may reduce the flexibility of the surfactant film and result in a compact film ${ }^{20)}$.

\subsection{Verification of the model and optimization}

The adequacy of the generated model was verified by performing several numbers of randomized formulations as presented in Table 4. All data were verified by comparing the experimental and predicted values to determine the percentage of residual standard error (RSE \%). The RSE values showed no significant difference which indicated that the model is acceptable for development of PHNE. The optimized PHNE formulation was recommended by Design Expert by taking into account the lowest amount of surfactant and a high amount of crude extract. The low RSE value (1.96) indicated the model was in a good agreement between the experimental and predicted values of particle size.

\subsection{Stability study}

The optimized PHNE was subjected to various condition to accelerate changes that may challenge the stability of the formulation including flocculation, Ostwald ripening, coalescence, and gravitational separation (creaming and sedimentation). From the centrifugation test and storage at $25^{\circ} \mathrm{C}$ and $45^{\circ} \mathrm{C}$, the nanoformulated was shown to be physically stable against creaming, crystal precipitation, cracking, or phase separation. This suggested that the opti- 
Optimization and Characterization of P. hysterophorus Nanoemulsion for Herbicide Formulation

Table 4 The experimental and predicted response for randomized formulation.

\begin{tabular}{|c|c|c|c|c|c|c|}
\hline \multirow{2}{*}{ Oil (\%) } & \multirow{2}{*}{ Surfactant (\%) } & \multirow{2}{*}{ Water $(\%)$} & \multirow{2}{*}{ Extract (\%) } & \multicolumn{2}{|c|}{ Particle size (nm) } & \multirow{2}{*}{ RSE (\%) } \\
\hline & & & & Experimental & Predicted & \\
\hline \multicolumn{7}{|c|}{ Verification Set } \\
\hline 32.00 & 38.00 & 28.00 & 7.00 & 132.50 & 131.65 & 0.65 \\
\hline 37.00 & 28.00 & 22.00 & 13.00 & 177.60 & 176.90 & 0.40 \\
\hline 31.60 & 25.00 & 25.40 & 18.00 & 174.43 & 177.13 & 1.50 \\
\hline \multicolumn{7}{|c|}{ Optimization Set } \\
\hline 30.91 & 28.48 & 28.32 & 12.29 & 140.10 & 137.41 & 1.96 \\
\hline
\end{tabular}

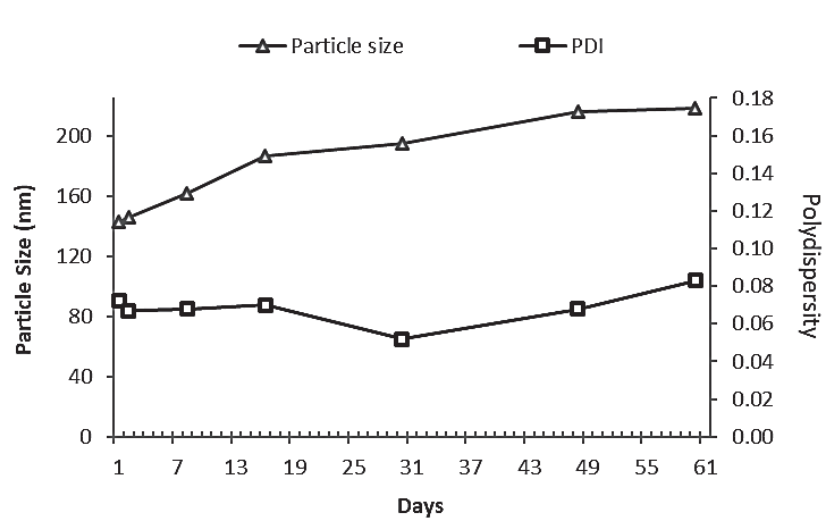

Fig. 3 Changes in particle size and PDI of optimized PHNE within 60 days of storage at $25^{\circ} \mathrm{C}$.

mized PHNE was stable against gravitational separation. Furthermore, the characterization and stability assessment of nanoemulsion is strongly associated with their particle size, PDI and zeta potential values. The optimized PHNE was subjected to long term stability test at room temperature for 60 days since the breakdown of emulsion system may occur on storage of the product depending on the particle size distribution and density difference between the particles and the medium. Figure 3 showed that after storage for 60 days, a slight increase in terms of particle size was observed from 143 to $218 \mathrm{~nm}$.

Over this 60 day of storage, PDI values have a narrow distribution in the range of 0.07 to 0.08 from day 1 to day 60 . The small value indicated less deviation from the average size and known as monodisperse. Values below 0.2 were considered as an ideal particle homogeneity ${ }^{21)}$, where changes of polydispersity of a system were often associated with stability issues ${ }^{22}$ such as flocculation and coalescence $^{23)}$. Stability of nanoemulsion to flocculation and coalescence could be improved as the particle size get smaller due to the strength of the attractive forces decreases more rapidly than the strength of the repulsive forces. High polydispersity value was an indication of diameter heterogeneity of particle populations in comparison to the initial particles (fresh sample) as a result of degradation, aggregation, or disintegration ${ }^{21)}$. In most cases, both flocculation and coalescence would lead to a broadening parti-

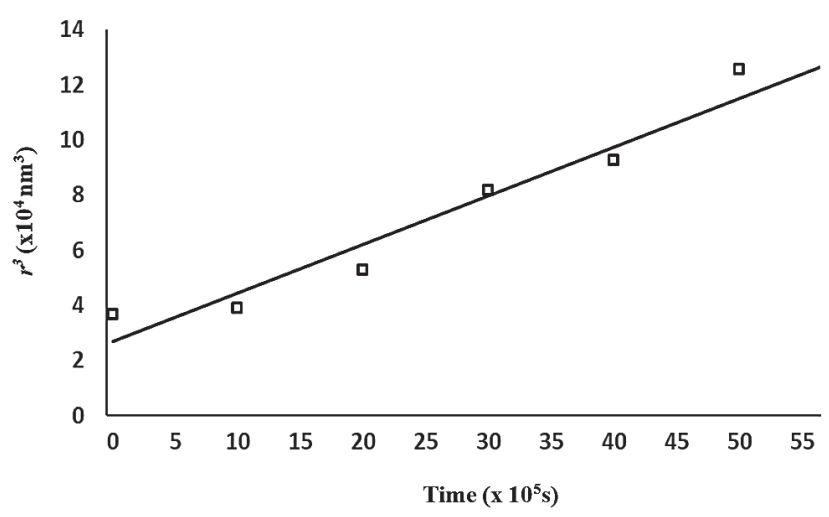

Fig. $4 \quad r^{3}$ as a function of time for optimized PHNE.

cle size distribution (higher PDI value ${ }^{24)}$ which was not observed in this study.

On the other hand, zeta potential is one of the stability parameters associated to surface potential of the emulsion particles. After 60 days, the zeta potential values were changed to less negative from -32.70 to -26.80 . Generally, zeta potential value of $+/-30 \mathrm{mV}$ was considered as a stable nanoemulsion. The value of zeta potential of formulation could be affected by the interaction between the amount of surfactant and oil. Sufficient amount of surfactant in comparison with the amount of oil could affect the stabilization of formulation by manipulating surface charge as a result of electrostatic repulsion between particles ${ }^{25)}$. High zeta potential value explained high repulsive electrostatic interaction between charged emulsion particles to prevent particle from getting closer. The values provide information of charge present on the particle surfaces where strong repulsive force preventing particle aggregation. The high stability was associated with a repulsive force which exceeds attracting Van der Walls forces and produced dispersed particles of a deflocculated system ${ }^{20}$.

In this study, the increasing particle size over time could be contributed by Ostwald ripening. Thus, a graph of $\mathrm{r}^{3}$ against time in second for the optimized PHNE was plotted to understand the reason behind the increment of particle size over time (Fig. 4). A linear relationship between $\mathrm{r}^{3}$ and time indicated the Ostwald ripening phenomenon ${ }^{15)}$ where the slope of the graph gave an Ostwald ripening rate of 

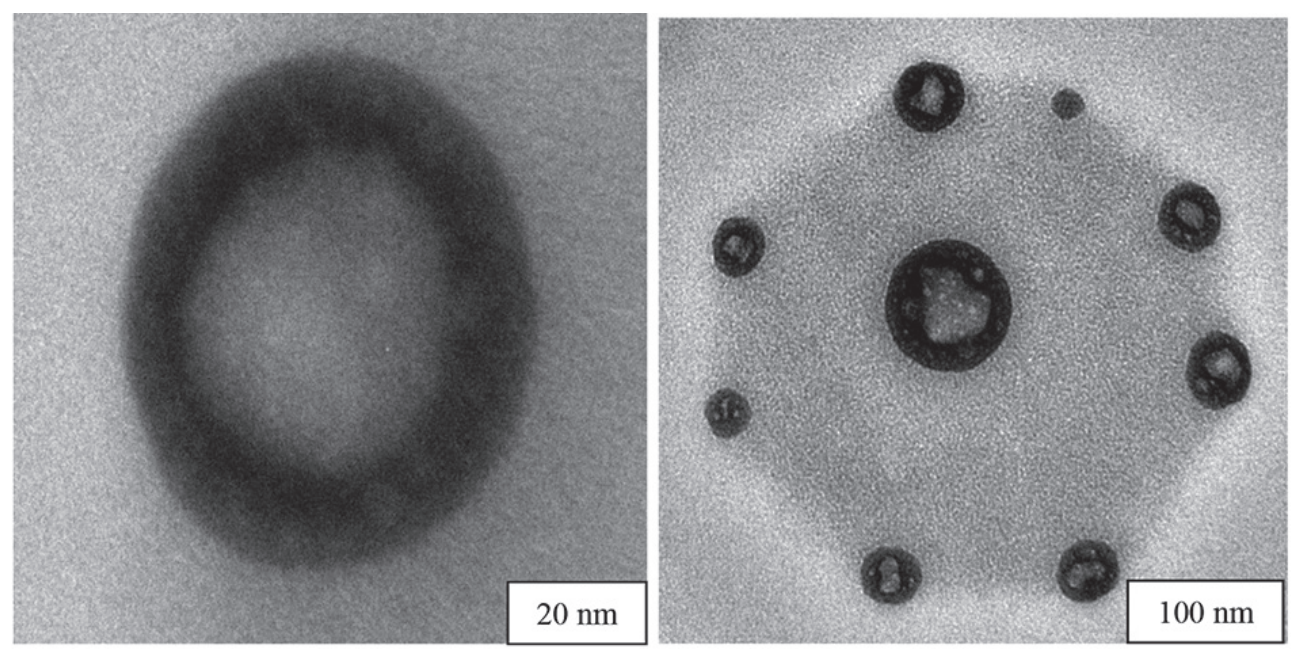

Fig. 5 Microstructure of the particle for optimized PHNE. Scale bar (a) $=20 \mathrm{~nm}$; (b) Scale bar $=100 \mathrm{~nm}$.

$0.1766 \mathrm{~nm}^{3} \mathrm{~s}^{-1}$. Ostwald ripening is referring to the deposition of smaller particles onto larger particles due to chemical potential differences of oil between particles of different sizes ${ }^{26,27)}$. It was known to be the main mechanism for nanoemulsion destabilization, and the rate can be determined by referring to Lifshitz-Slesov-Wagner theory ${ }^{28)}$. The ongoing normal phenomenon could be controlled by increasing the solubility of the disperse phase in the continuous phase to create the thermodynamic driving force ${ }^{15}$.

\subsection{Morphology analysis}

The morphological observation of formulated nanoemulsion system was revealed in Fig. 5. The nanoemulsion particles were shown to be spherical with a diameter below $200 \mathrm{~nm}$. The oil droplet containing PHCE was shown in bright colour encapsulated in the colloidal system. The image portrayed clear phase boundaries of the particles shells indicating high physical stability of the system. Instability such as aggregates and particles deformation can be seen from FEM image if the excess amount of surfactant ${ }^{29)}$ or imbalance composition of the formulation was in the system.

\subsection{Surface tension analysis}

The surface tension of the oil-water interface at different concentration of PHCE and PHNE was illustrated in Fig. 6. The decay in dynamic surface tension over increasing PHCE and PHNE concentrations indicates that both treatments were surface active and can reduce the surface tension of pure distilled water from 72.94 to $38.62 \mathrm{mN} \mathrm{m}^{-1}$ for PHCE and from 72.94 to $37.32 \mathrm{mN} \mathrm{m}^{-1}$ for PHNE. In this study, PHCE contained saponin ${ }^{30)}$ which work as a natural emulsifier by having hydrophobic parts from triterpene or steroid backbone covalently bond to hydrophilic parts such as carbohydrate groups ${ }^{31}$. While the present of surfactant(Tensiofix and Tween 80)in PHNE have in-

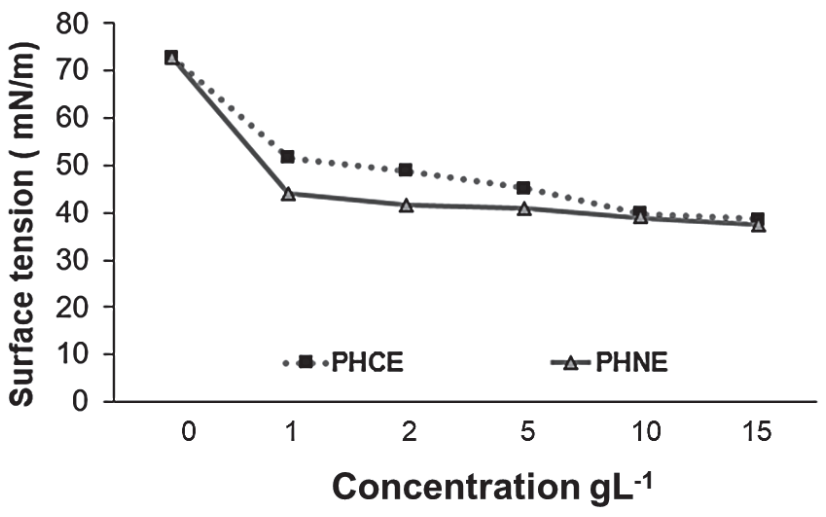

Fig. 6 Surface tension of oil-water interface at different concentration of PHCE and PHNE.

creased the ability of PHCE in reducing the interfacial tension of water. Surfactant works by aligning themselves randomly on the liquid surface with hydrophilic head in the water and hydrophobic tail in oil. Tween 80 is considered as a strong solubilizer due to the extent of packing at the interface and structure similarity between the lipophilic tail of the oleyl group and oleyl group of the $\mathrm{PKOE}^{10)}$. In comparison to study done by Lim et $a l^{4}{ }^{4}$, the value of surface tension from this study is lower than the surface tension of commercial herbicide formulation $\left(47.8 \mathrm{mN} \mathrm{m}^{-1}\right)$.

Surfactants play a vital role in contributing for the stability of a nanoemulsion system because they facilitate in the formation of small particles by absorbing to the oil-water interface and reduced the interfacial tension ${ }^{32}$. Reduction of surface tension by a surfactant is also an important property for pre emergence herbicide formulation as it contributing for penetration of bioactive to the hydrophobic surface of plant ${ }^{33)}$. This is because, seeds were protected by seed coat from harmful external factors where seed coat can have selective permeability. Any substance failed 
Table 5 Germination percentage (GP) for D. ocimifolia seed treated by different concentrations of PHCE and PHNE.

\begin{tabular}{ccc}
\hline Sample & Concentration $\left(\mathrm{g} \mathrm{L}^{-1}\right)$ & GP $(\%)$ \\
\hline Control & 0 & $75.00 \pm 3.53^{\mathrm{ab}}$ \\
& 1 & $83.75 \pm 8.93^{\mathrm{a}}$ \\
PHCE & 2 & $68.75 \pm 6.50^{\mathrm{b}}$ \\
& 5 & $8.75 \pm 4.15^{\mathrm{d}}$ \\
& 10 & $0.00 \pm 0.00$ \\
& 15 & $0.00 \pm 0.00$ \\
PHNE & 1 & $70.00 \pm 3.54^{\mathrm{ab}}$ \\
& 2 & $31.25 \pm 7.40^{\mathrm{c}}$ \\
& 5 & $0.00 \pm 0.00$ \\
& 10 & $0.00 \pm 0.00$ \\
\hline
\end{tabular}

Data are mean $( \pm \mathrm{S} . \mathrm{E})$ of four replicates. Means by different superscript letter $\left({ }^{a}\right.$ to $\left.{ }^{\mathrm{d}}\right)$ are significantly different at $p<0.05$

to pass through the seed coat, will not affect the germination process ${ }^{5)}$. Low surface tension allows the formulation to be deposited on the surface of seed with lower contact angle and further increased spreading and wetting properties. It is therefore essential to have a herbicide formulation containing a surfactant to help stabilized the system and increased the efficiency of herbicide formulation to absorb into the seed coat.

\subsection{Germination bioassay study}

Table 5 showed the germination percentage (GP) of $D$. ocimifolia seed as affected by PHCE and PHNE in different concentrations. PHNE was shown to have higher toxicity towards germination of $D$. ocimifolia seeds. The lowest concentration to totally inhibit seed germination was decreased from $10 \mathrm{~g} \mathrm{~L}^{-1}$ in PHCE to $5 \mathrm{~g} \mathrm{~L}^{-1}$ in PHNE. The highest GP value was recorded by treatment at $1 \mathrm{~g} \mathrm{~L}^{-1}$ of PHCE $(83.75 \%)$. The GP value was higher than the control set $(75.00 \%)$ might be the effect of hormesis. Hormesis is a phenomenon where the toxicity acts as a stimulant at a low dose, but it is an inhibitor as increasing the treatment $\operatorname{dose}^{34)}$. However, hormesis was not shown in PHNE treatments where the highest GP value for PHNE was $70.00 \%$ which is lower than the GP value of control set $(75.75 \%)$. This is because PHNE treatment might give direct inhibition effect to the seed due to the small particle size (nano size) and the present of surfactant in nanoemulsion. The previous study has shown that anionic and cationic dye permeation was dependent on particle size where smaller particle size showed a significant diffusion across perisperm-endosperm envelope PE of cucumber seed ${ }^{35)}$. The study concluded that small particle size could help in pen-

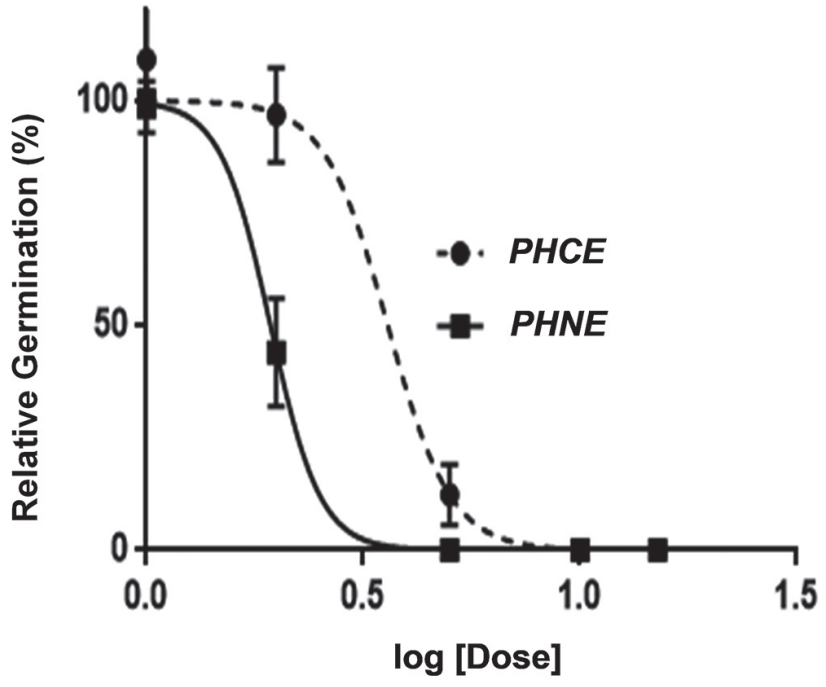

Fig. 7 Dose response curves represent biological inhibition of $D$. ocimifolia by PHCE and PHNE in concentration range $1-15 \mathrm{~g} \mathrm{~L}^{-1}$. The $\mathrm{ED}_{50}$ value of PHCE were extrapolated: $\mathrm{ED}_{50}=3.60 \mathrm{~g} \mathrm{~L}^{-1}: \mathrm{R}^{2}=$ 0.9787; $\mathrm{ED}_{50}$ value of PHNE were extrapolated: $\mathrm{ED}_{50}=1.93 \mathrm{~g} \mathrm{~L}^{-1}: \mathrm{R}^{2}=0.9888$.

etration of bioactive compound through plant seed coat ${ }^{35)}$.

Another observation for germination capacity was shown by dose response analysis in Fig. 7. The $\mathrm{ED}_{50}$ value of $\operatorname{PHNE}\left(1.93 \mathrm{~g} \mathrm{~L}^{-1}\right)$ was shown to be lower than the $\mathrm{ED}_{50}$ value of $\operatorname{PHCE}\left(3.60 \mathrm{~g} \mathrm{~L}^{-1}\right)$. Based on the $\mathrm{ED}_{50}$ result, the ability of PHCE to inhibit D. ocimifolia seed was almost doubled as plant extract being formulated in nanoemulsion system. Combination of the smart delivery system (nanoemulsion) and phytotoxic plant extract (PHCE) have reduced the amount of active ingredient from $1.93 \mathrm{~g} \mathrm{~L}^{-1}$ to $3.60 \mathrm{~g} \mathrm{~L}^{-1}$ for an effective inhibition result. The present of esterified vegetable oils, palm kernel oil ester(PKOE) as adjuvants in the formulation might have acted as a humectant or a solubilizing effect which increased the particle drying time on seed coat as investigated by Stock and Briggs $^{36)}$. This making PHNE as a delivery system to be more efficient than plant crude extract (PHCE) for herbicide formulation.

\section{Conclusion}

The findings of the research help to understand the development of naturally herbicide formulation containing palm oil derivatives and plant crude extract. Statistical tools such as MED was shown to be useful to find an optimum formulation composition which provides the smallest particle size. The optimization by MED produced a well-fitted quadratic model with low absolute errors. This indicates the efficiency of the model to develop herbicide 
formulation from plant crude extract. The optimized formulation was developed within nano size, physically stable at $25^{\circ} \mathrm{C}$ and $45^{\circ} \mathrm{C}$ storage and having the ability to reduce the surface tension of water. The formulated PHNE was also found to have a better inhibitory effect on $D$. ocimifolia seed germination as compared to PHCE in the in vitro germination study.

\section{Acknowledgements}

The author would like to thank the Ministry of Higher Education Malaysia(MOHE) for the financial support for Zainuddin N.J. under MyBrain15 Scholarship, and Department of Agriculture Malaysia for giving the permission and help during the collection of $P$. hysterophorus plant.

\section{References}

1) Patel, S. Harmful and beneficial aspects of Parthenium hysterophorus: an update. 3 Biotech. 1, 1-9 (2011).

2) Dhillon, N.K.; Mukhopadhyay, S.S. Nanotechnology and allelopathy : synergism in action. J. Crop Weed 11, 187-191 (2015).

3) Marwat, K.B.; Khan, M.A.; Nawaz, A.; Amin, A. Parthenium hysterophorus L. A potential source of bioherbicide. Pakistan J. Bot. 40, 1933-1942 (2008).

4) Lim, C.J.; Basri, M.; Omar, D.; Abdul Rahman, M.B.; Salleh, A.B.; Raja Abdul Rahman, R.N.Z. Green nanoemulsion-laden glyphosate isopropylamine formulation in suppressing creeping foxglove (A. gangetica), slender button weed $(D$. ocimifolia $)$ and buffalo grass $(P$. conjugatum). Pest Manag. Sci. 69, 104-11 (2013).

5) Lin, D.; Xing, B. Phytotoxicity of nanoparticles : Inhibition of seed germination and root growth. Environ. Pollut. 150, 243-250 (2007).

6) Main, D.C.; Sanderson, K.R.; Fillmore, S.A.E.; Ivany, J.A. Comparison of synthetic and organic herbicides applied banded for weed control in carrots (Daucus carota L.). Can. J. Plant Sci. 93, 857-861 (2013).

7) Vaughn, S.F.; Holser, R.A. Evaluation of biodiesels from several oilseed sources as environmental friendly contact herbicides. Ind. Crops Prod. 26, 63-68 (2007).

8) Sharma, S.D.; Singh, M. Optimizing foliar activity of glyphosate on Bidens frondosa and Panicum maximum with different adjuvant types. Weed Res. 40, 523-533(2000).

9) Keng, P.S.; Basri, M.; Zakaria, M.R.S.; Rahman, M.B.A.; Ariff, A.B.; Rahman, R.N.Z.A.; Salleh, A.B. Newly synthesized palm esters for cosmetics industry. Ind. Crops Prod. 29, 37-44 (2009).

10) Mahdi, E.S.; Sakeena, M.H.; Abdulkarim, M.F.; Abdul- lah, G.Z.; Sattar, M.A.; Noor, A.M. Effect of surfactant and surfactant blends on pseudoternary phase diagram behavior of newly synthesized palm kernel oil esters. Drug Des. Devel. Ther. 5, 311-323(2011).

11) Musa, S.H.; Basri, M.; Masoumi, H.R.F.; Shamsudin, N.; Salim, N. Enhancement of physicochemical properties of nanocolloidal carrier loaded with cyclosporine for topical treatment of psoriasis: In vitro diffusion and in vivo hydrating action. Int. J. Nanomedicine 12, 2427-2441 (2017).

12) Del Saz-orozco, B.; Oliet, M.; Alonso, M.V; Rojo, E.; Rodríguez, F. Formulation optimization of unreinforced and lignin nanoparticle-reinforced phenolic foams using an analysis of variance approach. Compos. Sci. Technol. 72, 667-674(2012).

13) Arbain, N.H.; Salim, N.; Wui, W.T.; Basri, M.; Basyaruddin, M.; Rahman, A. Optimization of quercetin loaded palm oil ester based nanoemulsion formulation for pulmonary delivery. J. Oleo Sci. 67, 1-8(2018).

14) Samson, S.; Basri, M.; Fard Masoumi, H.R.; Karjiban, R.A.; Malek, E.A. Design and development of a nanoemulsion system containing copper peptide by D-optimal mixture design and evaluation of its physicochemical properties. RSC Adv. 6, 17845-17856 (2016).

15) Kim, S.H.; Ji, Y.S.; Lee, E.S.; Hong, S.T. Ostwald ripening stability of curcumin-loaded MCT nanoemulsion: Influence of various emulsifiers. Prev. Nutr. Food Sci. 21, 289-295 (2016).

16) Jiang, L.C.; Basri, M.; Omar, D.; Abdul Rahman, M.B.; Salleh, A.B.; Raja Abdul Rahman, R.N.Z. Self-assembly behaviour of alkylpolyglucosides (APG) in mixed surfactant-stabilized emulsions system. J. Mol. Liq. 158, 175-181 (2011).

17) Komaiko, J.; McClements, D.J. Low-energy formation of edible nanoemulsions by spontaneous emulsification: Factors influencing particle size. J. Food Eng. 146, 122-128(2015).

18) Lim, C.J.; Basri, M.; Omar, D.; Abdul Rahman, B.; Salleh, A.B.; Raja Abdul Rahman, R.N.Z. Physicochemical characterization and formation of glyphosate-laden nano-emulsion for herbicide formulation. Ind. Crops Prod. 36, 607-613(2012).

19) Dias, D.D.O.; Colombo, M.; Kelmann, R.G.; Kaiser, S.; Lucca, L.G.; Teixeira, H.F.; Limberger, R.P.; Veiga, V.F.; Koester, L.S. Optimization of copaiba oil-based nanoemulsions obtained by different preparation methods. Ind. Crops Prod. 59, 154-162 (2014).

20) Fernandes, C. Development of an insecticidal nanoemulsion with Manilkara subsericea (Sapotaceae) extract. J. Nanobiotechnol. 12, 1-9(2014).

21) Grillo, R.; dos Santos, N.Z.P.N.Z.P.; Maruyama, C.R.C.R.; Rosa, A.H.A.H.; de Lima, R.; Fraceto, L.F. Poly (e\{open\}-caprolactone) nanocapsules as carrier systems for herbicides: Physico-chemical characteriza- 
tion and genotoxicity evaluation. J. Hazard. Mater. 231-232, 1-9 (2012).

22) Zorzi, G.; Carvalho, E.; von Poser, G.; Teixeira, H.F. On the use of nanotechnology based strategies for association of complexes matrices from plant extracts. Rev. Bras. Farmacogn. 25, 426-436 (2015).

23) McClements, D.J.; Rao, J. Food-grade nanoemulsions: Formulation, fabrication, properties, performance, biological fate, and potential toxicity. Crit. Rev. Food Sci. Nutr. 51, 285-330 (2011).

24) Saberi, A.H.; Fang, Y.; McClements, D.J. Fabrication of vitamin E-enriched nanoemulsions: Factors affecting particle size using spontaneous emulsification. J. Colloid Interface Sci. 391, 95-102 (2013).

25) Musa, S.H.; Basri, M.; Masoumi, H.R.F.; Karjiban, R.A.; Malek, E.A.; Basri, H.; Shamsuddin, A.F. Formulation optimization of palm kernel oil esters nanoemulsionloaded with chloramphenicol suitable for meningitis treatment. Colloids Surf. B 112, 113-119(2013).

26) Delmas, T.; Piraux, H.; Couffin, A.C.; Texier, I.; Vinet, F.; Poulin, P.; Cates, M.E.; Bibette, J. How to prepare and stabilize very small nanoemulsions. Langmuir 27, 1683-1692 (2011).

27) Tadros, T.F. Emulsion Formation, Stability, and Rheology. Wiley-VCH Verlag GmbH \& Co. KGaA (2013).

28) Lifshitz, I.M.; Slyozov, V.V. The kinetics of precipitation from supersaturated solid solutions. J. Phys. Chem. Solids. 19, 35-50 (1961).

29) Klang, V.; Matsko, N.B.; Valenta, C.; Hofer, F. Electron microscopy of nanoemulsions: An essential tool for characterisation and stability assessment. Micron 43,
85-103 (2012).

30) Shah, B.A.; Chib, R.; Gupta, P.; Sethi, K.; Koul, S.; Andotra, S.S.; Nargotra, A.; Sharma, S.; Pandey, A.; Bani, S.; Purnima, B.; Chandra, S. Saponins as novel TNF- a inhibitors : isolation of saponins and a nor-pseudoguaianolide from Parthenium hysterophorus. Org. Biomol. Chem. 7, 3230-3235 (2009).

31） Shu, G.; Khalid, N.; Chen, Z.; Neves, M.A.; Barrow, C.J.; Nakajima, M. Formulation and characterization of astaxanthin-enriched nanoemulsions stabi- lized using ginseng saponins as natural emulsifiers. Food Chem. 255, 67-74 (2018).

32) Bai, L.; Huan, S.; Gu, J.; McClements, D.J. Fabrication of oil-in-water nanoemulsions by dual-channel microfluidization using natural emulsifiers : Saponins, phospholipids, proteins, and polysaccharides. Food Hydrocoll. 61, 703-711 (2016).

33) Du, Z.; Wang, C.; Tai, X.; Wang, G.; Liu, X. Optimization and characterization of biocompatible oil-in-water nanoemulsion for pesticide delivery. ACS Sustain. Chem. Eng. 4, 983-991 (2016).

34) Dragicevic, M.; Platisa, J.; Nikolic, R.; Todorovic, S.; Bogdanovic, M.; Mitic, N.; Simonovic, A. Herbicide phosphinothricin causes direct stimulation hormesis. Dose-Response 11, 344-360 (2013).

35) Amritphale, D.; Ramakrishna, P.; Singh, B.; Sharma, S.K. Solute permeation across the apoplastic barrier in the perisperm-endosperm envelope in cucumber seeds. Planta 231, 1483-1494(2010).

36) Stock, D.; Briggs, G. Physicochemical properties of adjuvants: Values and applications. Weed Technol. 14, 798-806 (2000). 